\title{
Prediction by using Artificial Neural Networks and Box-Jenkins methodologies: Comparison Study
}

Emaan Yousif Abdoon

\author{
Al -Qadisiyah University \\ College of Computer Science \& \\ Information Technology \\ Department of Mathematics
}

emaan.yousif1991@gmail.com

Recived : 917/2017
Revised : //
Mohammed Habib Al- Sharoot

\author{
Al-Qadisiyah University \\ College of Administration \& Economics
}

Department of Statistics

m.alsharood@gmail.com

\begin{abstract}
The variations in exchange rate, especially the sudden unexpected increases and decreases, have significant impact on the national economy of any country. Iraq is no exception; therefore, the accurate forecasting of exchange rate of Iraqi dinar to US dollar plays an important role in the planning and decision-making processes as well as the maintenance of a stable economy in Iraq. This research aims to compare Box-Jenkins methodology to neural networks in terms of forecasting the exchange rate of Iraqi dinar to US dollar based on data provided by the Iraqi Central Bank for the period 30/01/2004 and 30/12/2014.
\end{abstract}

Based on the Mean Square Error (MSE), the Mean Absolute Error (MAE), and the Mean Absolute Percentage Error (MAPE) as criteria to compare the two methodologies, it was concluded that BoxJenkins is better than neural network approach in forecasting.

Keywords: Time series analysis, Autoregressive Moving Average models, Artificial neural network, Backpropagation algorithm.

\section{1- Time series $[1,2,3]$}

Time series is a sequence of observations of a specific phenomenon throughout a previous time period. Usually, these observations are dependent and organized according to time. Time series can be classified to two types: stationary and non-stationary time series. The word stationary refers to the absence of growth in the data meaning that the data fluctuate around a constant level without any increasing or decreasing trend. Therefore, time series can be stationary if it has the two following conditions:

a. mean stationary

$$
E\left(W_{t}\right)=\mu \text { for all } t(1)
$$

b. variance stationary

$$
\begin{aligned}
\operatorname{Var}\left(W_{t}\right)= & E\left(W_{t}-\mu\right)^{2} \\
& =\gamma_{0} \text { for all } t(2)
\end{aligned}
$$


Emaan .Y / Mohammed .H

In practice, most of time series, especially economic series, are non-stationary and difficult to model. Therefore, series that are not mean stationary can be transformed to stationary by taking the differences of $\mathrm{d}$ degree as follow:

$$
(1-L)^{d} Y_{t}=Y_{t}-Y_{t-d}
$$

Where $\mathrm{L}$ is the backshift operator. The degree of differences usually equals to 1 or 2 .

The model of time series is a function that relates the current value of time series to the past values and adds the random error. This model is divided to three types:

\section{A. Autoregressive models [4]}

These models are often referred to as $\mathrm{AR}(\mathrm{p})$ and can be written in the following formula:

$$
\begin{aligned}
& W_{t}= \\
& \alpha_{1} W_{t-1}+\alpha_{2} W_{t-2}+\cdots+\quad \alpha_{p} W_{t-p}+u_{t}
\end{aligned}
$$

$\alpha_{j}$ : Autoregressive parameters and $\mathrm{j}=(1,2, \ldots$, p)

$W_{t}$ : Deviation of the original time series $Y_{t}$ from its mean

$u_{t}:$ Random error, $u_{t} \sim\left(0, \sigma_{u}^{2}\right) u_{t}$

\section{B. Moving Average Models [5]}

These models are often referred to as MA (q) and can be written in the following formula:

$W_{t}=u_{t}-\beta_{1} u_{t-1}-\beta_{2} u_{t-2}-\cdots-\beta_{q} u_{t-q}$

$\beta_{\tau}$ : Moving average parameters and $\tau=(1,2$, $\ldots, q)$

\section{Autoregressive Moving Average Models [3,6]}

These models are often referred to $\operatorname{ar} \operatorname{ARMA}(p, q)$ and can be written in the following formula:

$$
\begin{aligned}
& W_{t}=\alpha_{1} W_{t-1}+\alpha_{2} W_{t-2}+\cdots+\alpha_{p} W_{t-p}+ \\
& u_{t}-\beta_{1} u_{t-1}-\beta_{2} u_{t-2}-\cdots-\beta_{q} u_{t-q}
\end{aligned}
$$

\section{2- Box-Jenkins methodology $[7,8,4]$}

Introduced by Box and Jenkins in 1970, Box-Jenkins approach is one of the most distinguished statistical approaches to analyse the time series of specific phenomenon and forecasting the possible variations that may occur in the future based on previous observations of the phenomenon.

Box-Jenkins methodology mainly relies on representing stable data using autoregressive moving average models. This methodology consists of three repetitive phases including identification, parameters estimation, and diagnostic checking. The identification phase includes the selection of the proper model to represent the data and determining its rank after examining the stability of the data in the mean and variance by plotting the orginal time series, plotting the autocorrelation function of the data, and applying one of the three tests that include Augmented Dickey - Fuller (ADF), Phillips - Perron (P.P), and Kwiatkowski - Phillips Schmidt - Shin (KPSS).

If the time series is not mean stationary, appropriate number of differences can be taken to accomplish stationary in the mean. If the time series is not variance stationary, specific transformations can be taken, such as the log or the square root, to accomplish stability. In the second phase, the model is estimated using one of the estimation methods, such as Ordinary Least Square method, moments method, the conditional maximum likelihood, and the exact maximum likelihood method.

In the third phase, the randomization of residuals of the estimated model is examined by plotting the autocorrelation function of the residuals or applying Box- Pierce test, often referred to as $\mathrm{Q}_{\mathrm{BP}}$, or Ljung -Box test, often referred to as $\mathrm{Q}_{\mathrm{LB}}$. When the model pass the third phase successfully, the model is used to forecast 
the future values of the studied phenomenon using the following formula:

$$
\begin{aligned}
\widehat{W}_{t}(l)= & E\left(W_{t+l}\right) \\
& =\alpha_{1} E\left(W_{t+l-1}\right)+\cdots+\alpha_{p+d} E\left(W_{t+l-p-d}\right) \\
& -\beta_{1} E\left(u_{t+l-1}\right)-\ldots-\beta_{q} E\left(u_{t+l-q}\right)+ \\
& E\left(u_{t+l}\right)
\end{aligned}
$$

where $l$ represents the length of the forecasted time period.

\section{3-Artificial neural networks}

$$
[9,10,11,12,13,14,15,16]
$$

Artificial neural network is a computational technique that simulates the way human brain uses to perform a specific task. It consists of several processing units defined as neurons or nodes that are organized in three levels (layers) including input level, hidden level that consists of one or more hidden layer, and the output level. the nodes of each level are associated with the next level through connection force called weights, which work on saving the acquired knowledge from the training of network.

The nodes at the input level are called the input nodes and so on for the other levels. In addition, there is a node called the bias $b$ that has a positive value of one and has the same constant role in the regression model.

Each node of the hidden and output levels is provided with an activation function, linear or nonlinear, that works on processing the input signal and preventing the output of the processing node from reaching high value, which may stop the network leading to a failure of the training process.

Neural networks are divided to two types including single layer and multiple layer networks. The single layer network does not have the hidden level and contains one layer of weights that connects the input level to the output level. when applying the input signal $v_{j}$ in this type of network, we can obtain the output signal $z_{i}$ through the following formula:

$z_{i}=g\left(\sum_{j=1}^{R} x_{j} v_{j}+b_{i}\right) \quad: \quad i=1,2, \ldots, n$

Where

$\mathrm{x}_{\mathrm{j}}$ : weight

As for multi-layer networks, it has the ability to solve more complex problems because it contains the hidden level with one hidden layer or more. The output signal is obtained in this type of networks as follows

$\boldsymbol{Z}^{m}=\boldsymbol{g}^{m}\left(\boldsymbol{X}^{m} \boldsymbol{Z}^{m-1}+\boldsymbol{b}^{m}\right): m=1,2, \ldots, M(9)$

Where:

M: number of layers

$\mathrm{Z}^{\mathrm{m}-1}$ : output vector of the layer $\mathrm{m}-1$

$\mathrm{g}^{\mathrm{m}}:$ activation function of the layer $\mathrm{m}$

$b^{m}$ : bias vector of the layer $m$

$\mathrm{X}^{\mathrm{m}}$ : weights matrix of the layer $\mathrm{m}$

$\mathrm{Z}^{0}=\mathrm{V}$, and $\mathrm{V}$ is the input vector.

\section{(3-1) Backpropagation algorithm $[17,18]$}

The backpropagation algorithm is a generalization of the least mean squares algorithm where it is used to train multiple layers networks. It is often referred to as BP and is considered one of the most used algorithms among the supervised learning algorithms. It consists of three stages:

\section{1- Feed forward propagation stage $[10,19]$}

In this stage, inputs $\mathbf{Z}^{0}=\mathbf{V}$ are applied on the network and random initial weights $\mathbf{X}^{1}$ are generated in small values. In addition, this stage includes determining the learning rate $\eta$ and the momentum $\gamma$ by small value that falls within $(0,1)$ and $(1,0]$ respectively. Data are processed starting from the input layer to the output layer throughout 
the hidden layers. The outputs of the network are obtained using the following formula:

$$
\begin{aligned}
z_{j}^{m} & =g^{m}\left(s_{j}^{m}\right) \quad m=1,2, \ldots, M \\
& =g_{j}^{m}\left(\sum_{h=1}^{n^{m-1}} x_{j, h}^{m} z_{h}^{m-1}+b_{j}^{m}\right)
\end{aligned}
$$

Which can be written as a matrix

$$
\begin{aligned}
\boldsymbol{Z}^{m} & =\boldsymbol{g}^{m}\left(\boldsymbol{s}^{m}\right) \\
& =\boldsymbol{g}^{m}\left(\boldsymbol{X}^{m} \boldsymbol{Z}^{m-1}+\boldsymbol{b}^{m}\right)
\end{aligned}
$$

\section{2-Backward Propagation Stage $[10,16]$}

In this stage, the sensitivities $\boldsymbol{\delta}$ is calculated from the last layer, which represents the output layer, to the first layer throughout the hidden layers.

Sensitivity $\boldsymbol{\delta}^{\mathbf{M}}$ in the last layer $\mathbf{M}$ can be calculated using the following formula:

$\boldsymbol{\delta}^{M}=-2 \dot{\boldsymbol{G}}^{M}\left(\boldsymbol{s}^{M}\right)(\boldsymbol{d}-\boldsymbol{z})$

Where

\section{$d$ : desired output}

$z$ : calculated output by network

$\dot{\boldsymbol{G}}^{M}\left(\boldsymbol{s}^{M}\right)=$

$\left[\begin{array}{cccc}\dot{g}_{1}^{M}\left(s_{1}^{M}\right) & 0 & \cdots & 0 \\ 0 & \dot{g}_{2}^{M}\left(s_{2}^{M}\right) & \cdots & 0 \\ \vdots & \vdots & \vdots & \vdots \\ 0 & 0 & \cdots & \dot{g}_{n^{M}}^{M}\left(s_{n^{M}}^{M}\right)\end{array}\right]$ and

$\dot{g}_{j}^{M}\left(s_{j}^{M}\right)=\frac{\partial}{\partial s_{j}^{M}} g_{j}^{M}\left(s_{j}^{M}\right) j=1,2, \ldots, n^{M}(15)$

While sensitivity $\boldsymbol{\delta}^{m}$ in the hidden layer $\mathrm{m}$, where $\mathrm{m}=1,2, \ldots, \mathrm{M}-1$, can be calculated using the following formula:

$$
\boldsymbol{\delta}^{m}=\dot{\boldsymbol{G}}^{m}\left(\boldsymbol{s}^{m}\right)\left(\boldsymbol{X}^{m+1}\right)^{T} \boldsymbol{\delta}^{m+1}
$$

Where
$\dot{\boldsymbol{G}}^{m}\left(\boldsymbol{s}^{m}\right)=\left[\begin{array}{cccc}\dot{g}_{1}^{m}\left(s_{1}^{m}\right) & 0 & \cdots & 0 \\ 0 & \dot{g}_{2}^{m}\left(s_{2}^{m}\right) & \cdots & 0 \\ \vdots & \vdots & \vdots & \vdots \\ 0 & 0 & \cdots & \dot{g}_{n^{m}}^{m}\left(s_{n^{m}}^{m}\right)\end{array}\right]$

and

$$
\begin{aligned}
& \dot{g}_{j}^{m}\left(s_{j}^{m}\right)=\frac{\partial}{\partial s_{j}^{m}} g_{j}^{m}\left(s_{j}^{m}\right): j= \\
& 1,2, \ldots, n^{m}
\end{aligned}
$$

\section{3- Updating weights stage $[19,16]$}

After passing the feed forward propagation and the Backward Propagation stages, the stage of updating the weights and biases begins using the following formulas:

$\boldsymbol{X}^{m}(k)=\boldsymbol{X}^{m}(k-1)+\Delta \boldsymbol{X}^{m}(k-1)$

$\boldsymbol{b}^{m}(k)=\boldsymbol{b}^{m}(k-1)+\Delta \boldsymbol{b}^{m}(k-1)$

Where

1- In case of not using the momentum:

$$
\Delta \boldsymbol{X}^{m}(k-1)=-\eta \boldsymbol{\delta}^{m}\left(\mathbf{z}^{m-1}\right)^{T}
$$$$
\Delta \boldsymbol{b}^{m}(k-1)=-\eta \boldsymbol{\delta}^{m}
$$

2- In case of using the momentum:

$$
\begin{aligned}
\Delta \boldsymbol{X}^{m}(k-1)= & \gamma \Delta \boldsymbol{X}^{m}(k-2) \\
& -(1-\gamma) \eta \boldsymbol{\delta}^{m}\left(\mathbf{z}^{m-1}\right)^{T}
\end{aligned}
$$$$
\Delta \boldsymbol{b}^{m}(k-1)=\gamma \Delta \boldsymbol{b}^{m}(k-2)-(1-\gamma) \eta \boldsymbol{\delta}^{m}
$$

\section{4- Data}

The data used in this study is a time series of exchange rate of Iraqi dinar to the US dollar and was provided by the Iraqi Central Bank. The data consist of 132 monthly observations from 30/01/2004 to 30/12/2014 as show in table (1) below. 
Table 1: Exchange rate of Iraqi dinar to the US dollar

\begin{tabular}{|c|c|c|c|c|c|c|c|c|c|c|c|}
\hline month & $\mathbf{2 0 0 4}$ & $\mathbf{2 0 0 5}$ & $\mathbf{2 0 0 6}$ & $\mathbf{2 0 0 7}$ & $\mathbf{2 0 0 8}$ & $\mathbf{2 0 0 9}$ & $\mathbf{2 0 1 0}$ & $\mathbf{2 0 1 1}$ & $\mathbf{2 0 1 2}$ & $\mathbf{2 0 1 3}$ & $\mathbf{2 0 1 4}$ \\
\hline $\mathbf{1}$ & 1467 & 1453 & 1483 & 1323 & 1224 & 1179 & 1185 & 1185 & 1206 & 1226 & 1222 \\
\hline $\mathbf{2}$ & 1409 & 1459 & 1480 & 1299 & 1225 & 1178 & 1185 & 1185 & 1236 & 1231 & 1222 \\
\hline $\mathbf{3}$ & 1423 & 1469 & 1480 & 1290 & 1222 & 1178 & 1185 & 1185 & 1240 & 1255 & 1222 \\
\hline $\mathbf{4}$ & 1443 & 1474 & 1481 & 1284 & 1216 & 1179 & 1185 & 1187 & 1263 & 1267 & 1218 \\
\hline $\mathbf{5}$ & 1462 & 1473 & 1485 & 1275 & 1212 & 1187 & 1185 & 1196 & 1250 & 1270 & 1222 \\
\hline $\mathbf{6}$ & 1460 & 1468 & 1485 & 1269 & 1205 & 1180 & 1185 & 1197 & 1241 & 1237 & 1213 \\
\hline $\mathbf{7}$ & 1463 & 1476 & 1486 & 1261 & 1202 & 1184 & 1185 & 1197 & 1253 & 1218 & 1214 \\
\hline $\mathbf{8}$ & 1463 & 1480 & 1488 & 1253 & 1196 & 1184 & 1185 & 1199 & 1248 & 1209 & 1213 \\
\hline $\mathbf{9}$ & 1463 & 1481 & 1488 & 1249 & 1188 & 1183 & 1185 & 1200 & 1228 & 1211 & 1204 \\
\hline $\mathbf{1 0}$ & 1463 & 1475 & 1486 & 1245 & 1185 & 1183 & 1185 & 1200 & 1200 & 1220 & 1207 \\
\hline $\mathbf{1 1}$ & 1463 & 1477 & 1467 & 1240 & 1183 & 1183 & 1188 & 1200 & 1207 & 1218 & 1200 \\
\hline $\mathbf{1 2}$ & 1462 & 1479 & 1394 & 1216 & 1180 & 1185 & 1195 & 1218 & 1222 & 1222 & 1205 \\
\hline
\end{tabular}

\section{5- Box- Jenkins methodology application}

\section{The first stage: identification}

The time series of the exchange rate data was plotted as shown in figure (1) below

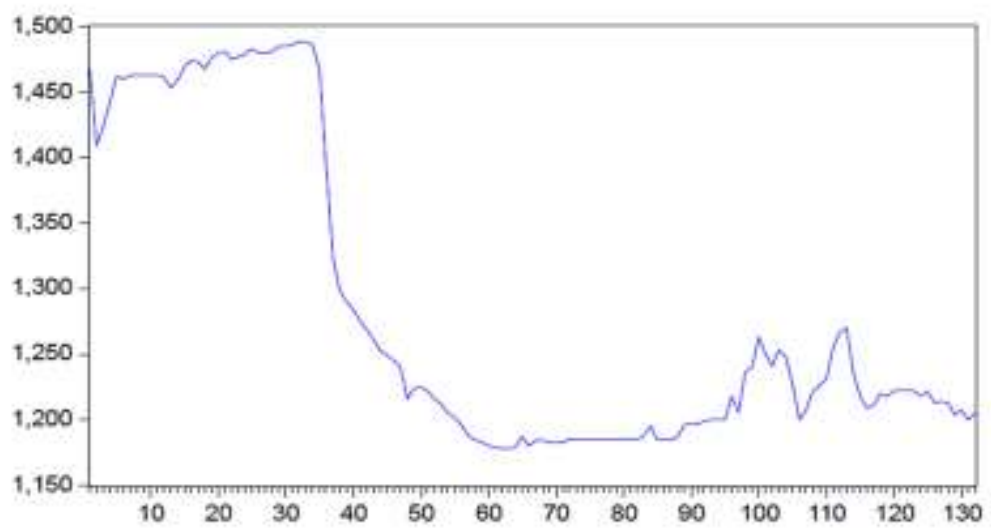

Figure 1: Exchange rate of Iraqi dinar to the US dollar

By looking at figure (1), we notice that the data $\mathrm{Y}_{\mathrm{t}}$ does not fluctuate around constant level, and it takes a decreasing trend which indicates that the time series is not mean stationary and not variance stationary.
To check the accuracy of results about the stationary of the time series in the mean, autocorrelation function and partial autocorrelation function were plotted for the raw data as shown in figure (2) below. 


\begin{tabular}{|c|c|c|c|c|c|c|c|c|}
\hline \multicolumn{9}{|c|}{$\begin{array}{l}\text { Sample: } 1132 \\
\text { Included observations: } 132\end{array}$} \\
\hline \multicolumn{2}{|c|}{ Autocorretation } & \multicolumn{2}{|c|}{ Partial Correlation } & & $A C$ & PAC & Q-Stat & Prob \\
\hline 1 & & 1 & & 1 & 0.982 & 0.982 & 130.20 & 0.000 \\
\hline 1 & & 1 & I & 2 & 0.964 & 0.000 & 256.73 & 0.000 \\
\hline 1 & & I & 1 & 3 & 0.943 & -0.101 & 378.76 & 0.000 \\
\hline 1 & & if & 1 & 4 & 0.920 & .0 .067 & 495.84 & 0.000 \\
\hline 1 & & 10 & 1 & 5 & 0.895 & -0.081 & 607.38 & 0.000 \\
\hline 1 & & 1 & 1 & 6 & 0.869 & -0.015 & 713,39 & 0.000 \\
\hline 1 & & 1 & 1 & 7 & 0.844 & 0.012 & 814.07 & 0.000 \\
\hline , & & , & , & 8 & 0.818 & 0.002 & 909.57 & 0.000 \\
\hline 1 & & it & 1 & 9 & 0.792 & -0.037 & 999.78 & 0.000 \\
\hline 1 & & 18 & 1 & 10 & 0.764 & .0 .062 & 1084,5 & 0.000 \\
\hline 1 & & 10 & 1 & 11 & 0.735 & -0.061 & 1163.5 & 0.000 \\
\hline 1 & & 17 & 1 & 12 & 0.704 & -0.058 & 1236.6 & 0.000 \\
\hline 1 & & 1 & 1 & 13 & 0.673 & -0.011 & 1304.0 & 0.000 \\
\hline 1 & & 1 & 1 & 14 & 0.642 & $=0.022$ & 1365.7 & 0.000 \\
\hline 1 & & 1 & I & 15 & 0.609 & .0 .044 & 1421.7 & 0.000 \\
\hline , & & 18 & 1 & 16 & 0.574 & -0.064 & 1471.9 & 0.000 \\
\hline 1 & 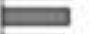 & 11 & 1 & 17 & 0.539 & -0.022 & 1516.7 & 0.000 \\
\hline 1 & 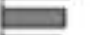 & 1 & 11 & 18 & 0.506 & 0.024 & 1556.4 & 0.000 \\
\hline 1 & $\square$ & 1 & 1 & 19 & 0.473 & -0.003 & 1591.5 & 0.000 \\
\hline 1 & $\square$ & 1 & 1 & 20 & 0.441 & $-0,004$ & 16222 & 0.000 \\
\hline 1 & $\square$ & 18 & 1 & 21 & 0.407 & -0.059 & 1648.6 & 0.000 \\
\hline 1 & $\square$ & 17 & 1 & 22 & 0.374 & -0.031 & 1671.0 & 0.000 \\
\hline 1 & 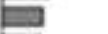 & 10 & 1 & 23 & 0.339 & .0 .052 & 1689.7 & 0.000 \\
\hline 11 & $\square$ & 11 & 1 & 24 & 0.304 & -0.030 & 17049 & 0.000 \\
\hline
\end{tabular}

Figure 2: Correlogram of raw data $Y_{t}$

By looking at figure (2), we notice that the autocorrelation function is slowly decreasing toward the zero and does not cut after the first and the second lag, which indicates that the raw data is not mean stationary.
To increase accuracy in the results about the stationary of the time series in the variance, ADF, P.P, and KPSS tests were applied as shown in table (2) below.

\begin{tabular}{|c|c|c|c|c|}
\hline Test & Model & Test Statistic & Critical Values & $\mathrm{p}$-Value \\
\hline \multirow{3}{*}{ ADF } & without constant & -0.837279 & $1.943304-$ & 0.3514 \\
\cline { 2 - 5 } & With constant & -0.979861 & $2.883756-$ & 0.7591 \\
\cline { 2 - 5 } & With constant and time trend & -1.307575 & $3.444756-$ & 0.8817 \\
\hline \multirow{3}{*}{ P.P } & without constant & -1.397307 & $1.943304-$ & 0.1504 \\
\cline { 2 - 5 } & With constant & -1.46627 & $2.883756-$ & 0.5477 \\
\cline { 2 - 5 } & With constant and time trend & -1.200101 & $3.444756-$ & 0.9059 \\
\hline \multirow{2}{*}{ KPSS } & With constant & 0.937165 & 0.643000 & \\
\cline { 2 - 5 } & With constant and time trend & 0.277682 & 0.146000 & \\
\hline
\end{tabular}


By checking the P-value of each model of the estimated models for both tests ADF and P.P at 0.05 significance level (alpha), we accept the null hypothesis and concluded that the time series has unit root meaning that it is not variance stationary. In addition, through ADF test, we concluded that the time series needs to take differences.

By comparing the calculated value of KPSS test statistic to the critical value, we accept the alternative hypothesis, which means that the time series is not variance stationary.
From the results of plots and tests, we conclude that the time series is not mean stationary and not variance stationary. Therefore, the log transformation was applied then the first difference was taken to accomplish stationary in the series in the variance and the mean respectively as shown in figure (3) which shows that the autocorrelation function of the transformed data is cut after the first lag, which indicates that the time series is mean stationary.

Corretogram of $\mathrm{W}$

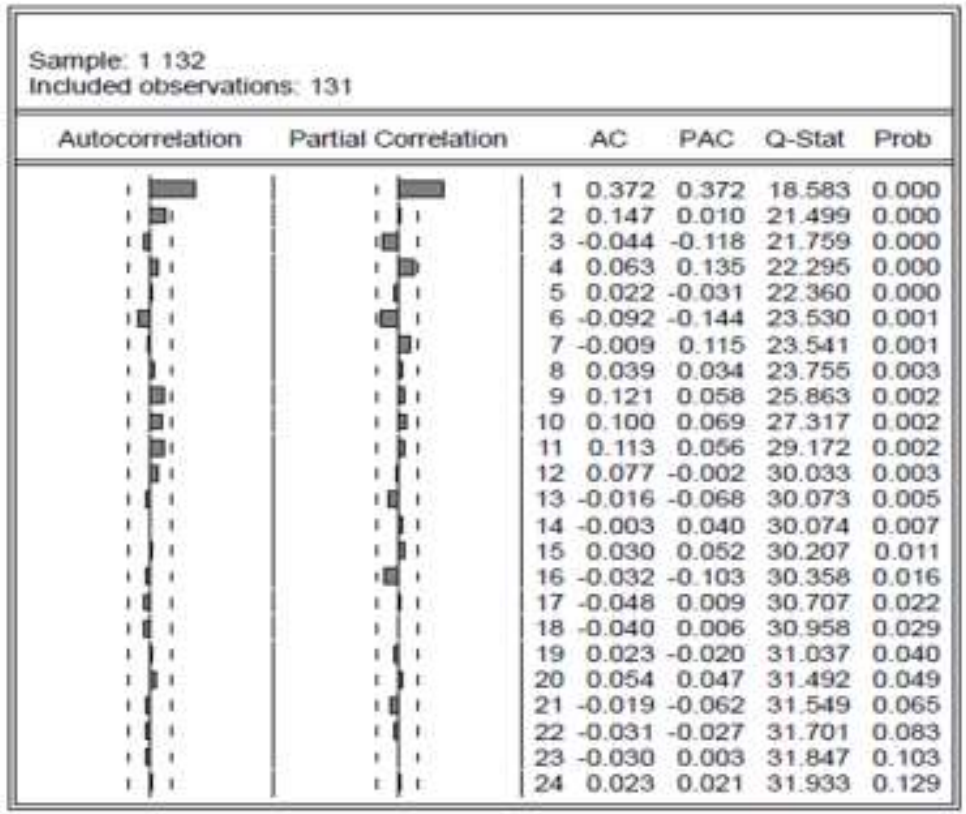

Figure 3: Correlogram of transformed data $W_{t}$

It becomes clear from the results of ADF, P.P, and KPSS tests of the transformed data, shown in table (3) below, that the time series is variance stationary. In addition, the results of
ADF indicate that the series does not need to take anymore differences, which indicates that the series is mean stationary. 
Table 3: The tests results of transformed data $W_{t}$

\begin{tabular}{|c|c|c|c|c|}
\hline Test & Model & Test Statistic & Critical Values & p-Value \\
\hline \multirow{3}{*}{ ADF } & without constant & -8.18208 & -1.943304 & 0.0000 \\
\cline { 2 - 5 } & With constant & $8.197312-$ & $2.883756-$ & 0.0000 \\
\cline { 2 - 5 } & With constant and time trend & $8.149873-$ & $3.444756-$ & 0.0000 \\
\hline \multirow{3}{*}{ P.P } & without constant & $8.344295-$ & $1.943304-$ & 0.0000 \\
\cline { 2 - 5 } & With constant & -8.382012 & $2.883756-$ & 0.0000 \\
\cline { 2 - 5 } & With constant and time trend & $8.343332-$ & $3.444756-$ & 0.0000 \\
\hline \multirow{2}{*}{ KPSS } & With constant & 0.214289 & 0.643000 & \\
\cline { 2 - 5 } & With constant and time trend & 0.098436 & 0.146000 & \\
\hline
\end{tabular}

In this stage, the suggested primary model $\operatorname{ARIMA}(1,1,1)$ has been estimated by the Exact Maximum Likelihood method. Some models have been suggested which are very closes to the primary model as: $\operatorname{ARIMA}(1,1,0), \quad \operatorname{ARIMA}(2,1,0)$, $\operatorname{ARIMA}(2,1,2)$, $\operatorname{ARIMA}(2,1,1)$, $\operatorname{ARIMA}(1,1,2)$ and ARIMA $(0,1,1)$ model as shown in table (4) below

\section{4: estimated parameters of ARIMA (p,d,q) models}

\begin{tabular}{|c|c|c|c|c|c|c|c|}
\hline ARIMA & \multicolumn{2}{|c|}{ parameters } & P-Value & ARIMA & \multicolumn{2}{|c|}{ parameters } & P-Value \\
\hline$(2,1,2)$ & $\hat{\alpha}_{1}$ & 0.180371 & 0.1145 & $(2,1,1)$ & $\hat{\alpha}_{1}$ & 0.866848 & 0.5128 \\
\hline & $\hat{\alpha}_{2}$ & 0.501118 & $06 \mathrm{e}-4.14$ & & $\hat{\alpha}_{2}$ & $0.227888-$ & 0.6809 \\
\hline & $\hat{\beta}_{1}$ & 0.635411 & $\mathrm{e}-0151.28$ & & $\hat{\beta}_{1}$ & $0.412057-$ & 0.7584 \\
\hline & $\hat{\beta}_{2}$ & 0.834250 & $\mathrm{e}-0347.00$ & $(0,1,1)$ & $\hat{\beta}_{1}$ & 0.0347870 & $\mathrm{e}-053.32$ \\
\hline$(1,1,2)$ & $\hat{\alpha}_{1}$ & $0.332391-$ & 0.0773 & $(2,1,0)$ & $\hat{\alpha}_{1}$ & 0.443303 & $3.82 \mathrm{e}-06$ \\
\hline & $\hat{\beta}_{1}$ & 0.836455 & $07 \mathrm{e}-4.24$ & & $\hat{\alpha}_{2}$ & -0.0253968 & 0.7905 \\
\hline & $\hat{\beta}_{2}$ & 0.515426 & $09 \mathrm{e}-4.44$ & & & & \\
\hline$(1,1,0)$ & $\hat{\alpha}_{1}$ & 0.431265 & $08 \mathrm{e}-6.57$ & & & & \\
\hline$(1,1,1)$ & $\hat{\alpha}_{1}$ & 0.404445 & 0.0293 & & & & \\
\hline & $\hat{\beta}_{1}$ & 0.0338880 & 0.8672 & & & & \\
\hline
\end{tabular}

To select the best model among the estimated models to represent the data, some statistical criteria including AIC, BIC, H-Q, MSE, MAE,
MPE, and MAPE were calculated as shown in table (5) below. 
Table 5: Estimated criteria of ARIMA (p, d, q) models

\begin{tabular}{|c|c|c|c|c|c|}
\hline ARIMA & \multicolumn{2}{|c|}{ Criterion } & ARIMA & \multicolumn{2}{|c|}{ Criterion } \\
\hline$(2,1,2)$ & $\mathrm{AIC}$ & -856.1266 & $(2,1,1)$ & AIC & -846.4964 \\
\hline & H-Q & -850.2850 & & $\mathrm{H}-\mathrm{Q}$ & -841.8231 \\
\hline & $\mathrm{BIC}$ & -841.7506 & & $\mathrm{BIC}$ & -834.9956 \\
\hline & MSE & $8.2251 \mathrm{e}-005$ & & MSE & $8.8286 \mathrm{e}-005$ \\
\hline & MAE & 0.0055517 & & MAE & 0.005339 \\
\hline & MPE & -0.014625 & & MPE & -0.012791 \\
\hline & MAPE & 0.077613 & & MAPE & 0.074591 \\
\hline$(1,1,2)$ & AIC & -855.4026 & $(0,1,1)$ & AIC & -845.4281 \\
\hline & $\mathrm{H}-\mathrm{Q}$ & -850.7329 & & H-Q & -843.0915 \\
\hline & $\mathrm{BIC}$ & -843.9054 & & $\mathrm{BIC}$ & -839.6777 \\
\hline & MSE & $8.4133 \mathrm{e}-005$ & & MSE & $9.0732 \mathrm{e}-005$ \\
\hline & MAE & 0.005490 & & MAE & 0.0054472 \\
\hline & MPE & -0.012031 & & MPE & -0.015472 \\
\hline & MAPE & 0.076745 & & MAPE & 0.076101 \\
\hline$(1,1,0)$ & $\mathrm{AIC}$ & -850.1698 & $(2,1,0)$ & AIC & -848.2394 \\
\hline & $\mathrm{H}-\mathrm{Q}$ & -847.8332 & & $\mathrm{H}-\mathrm{Q}$ & -844.7344 \\
\hline & $\mathrm{BIC}$ & -844.4194 & & $\mathrm{BIC}$ & -839.6138 \\
\hline & MSE & $8.8425 \mathrm{e}-005$ & & MSE & $8.8399 \mathrm{e}-005$ \\
\hline & MAE & 0.0053075 & & MAE & 0.005309 \\
\hline & MPE & -0.011707 & & MPE & -0.012026 \\
\hline & MAPE & 0.074140 & & MAPE & 0.074167 \\
\hline$(1,1,1)$ & AIC & -848.2102 & & & \\
\hline & H-Q & -844.7053 & & & \\
\hline & $\mathrm{BIC}$ & -839.5846 & & & \\
\hline & MSE & $8.8409 \mathrm{e}-005$ & & & \\
\hline & MAE & 0.0053073 & & & \\
\hline & MPE & -0.011881 & & & \\
\hline & MAPE & 0.074141 & & & \\
\hline
\end{tabular}

Based on the significance of estimated parameters shown in table (4) and the values of criteria shown in table (5), ARIMA $(1,1,0)$ model was selected to represent the data. We can also conclude from table (4) that ARIMA $(1,1,0)$ model fulfills the stationary condition $\left|\alpha_{1}\right|=|0.431265|<1$.
The third stage: Diagnostic Checking

To ensure the efficiency of ARIMA $(1,1,0)$ model in representing the data, the model residuals were tested by calculating and plotting the autocorrelation function of the residuals as shown in figure (4) and table (6).

By looking at figure (4) and table (6), we notice that all autocorrelation cofficients of the model residuals fall within trust limits and do not significantly differ from zero, which indicates that the residuals represent the white noise. 
Journal of AL-Qadisiyah for computer science and mathematics Vol.9 No.2 Year 2017 ISSN (Print): 2074 - 0204 ISSN (Online): 2521 - 3504

Emaan .Y / Mohammed .H

Table 6: Autocorrelation coefficients of residuals for ARIMA $(1,1,0)$ model

\begin{tabular}{|c|c|c|c|c|c|c|}
\hline $\begin{array}{l}* \star *, \\
\text { using }\end{array}$ & $\begin{array}{l}*,+ \text { indi } \\
\text { standard }\end{array}$ & $\begin{array}{l}\text { cate } \\
\text { exrox }\end{array}$ & $\begin{array}{c}\text { significa } \\
1 / \mathrm{T} 0.5\end{array}$ & ince at & the & levels \\
\hline IAG & $\mathrm{ACF}$ & & PACF & & $Q-s t a t$. & [p-value] \\
\hline 1 & -0.0611 & & -0.0611 & & & \\
\hline 2 & 0.0356 & & 0.0320 & & 0.6711 & {$[0.413]$} \\
\hline 3 & -0.1628 & * & -0.1595 & * & 4.2781 & {$[0.118]$} \\
\hline 4 & 0.0954 & & 0.0785 & & 5.5278 & {$[0.137]$} \\
\hline 5 & 0.0436 & & 0.0636 & & 5.7907 & {$[0.2151$} \\
\hline 6 & -0.1304 & & -0.1623 & $*$ & 8.1607 & {$[0.148]$} \\
\hline 7 & 0.0123 & & 0.0269 & & 8.1820 & {$[0.225]$} \\
\hline 8 & -0.0017 & & 0.0213 & & 8.1824 & {$[0.317]$} \\
\hline 9 & 0.0962 & & 0.0384 & & 9.5039 & {$[0.302]$} \\
\hline 10 & 0.0209 & & 0.0599 & & 9.5669 & {$[0.387]$} \\
\hline 11 & 0.0669 & & 0.0837 & & 10.2172 & {$[0.422]$} \\
\hline 12 & 0.0562 & & 0.0626 & & 10.6791 & {$[0.471]$} \\
\hline 13 & -0.0584 & & -0.0579 & & 11.1820 & {$[0.513]$} \\
\hline 14 & -0.0114 & & -0.0075 & & 11.2015 & {$[0.594]$} \\
\hline 15 & 0.0595 & & 0.0941 & & 11.7331 & {$[0.628]$} \\
\hline 16 & -0.0329 & & -0.0635 & & 11.8971 & {$[0.687]$} \\
\hline 17 & -0.0298 & & -0.0230 & & 12.0331 & {$[0.742]$} \\
\hline 28 & -0.0434 & & 0.0033 & & 12.3232 & {$[0.780]$} \\
\hline 19 & 0.0185 & & -0.0419 & & 12.3764 & {$[0.827]$} \\
\hline 20 & 0.0718 & & 0.0548 & & 13.1848 & {$[0.829]$} \\
\hline 21 & -0.0372 & & -0.0248 & & 13.4037 & {$[0.859]$} \\
\hline 22 & -0.0138 & & -0.0360 & & 13.4342 & {$[0.893]$} \\
\hline 23 & -0.0367 & & -0.0221 & & 13.6509 & {$[0.913]$} \\
\hline 24 & 0.0503 & & 0.0165 & & 14.0623 & {$[0.925]$} \\
\hline
\end{tabular}

Residual ACF

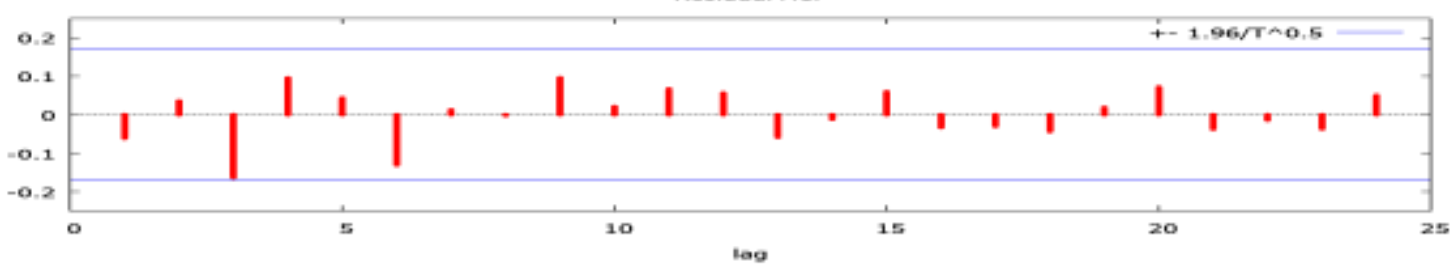

Residual PACF

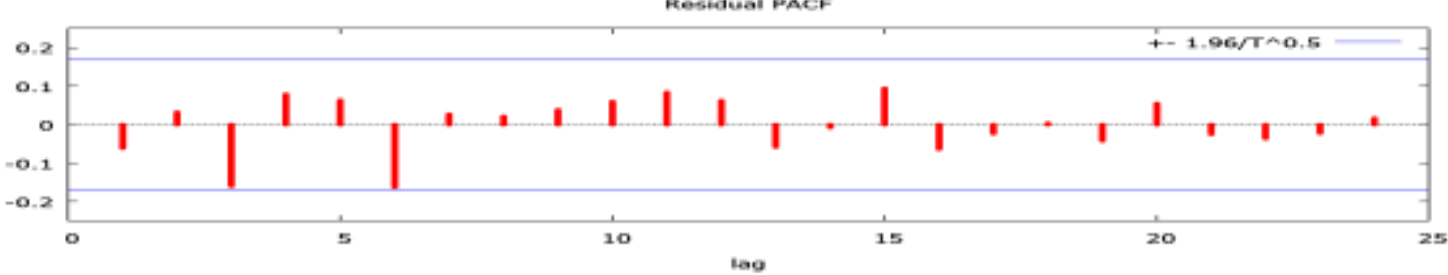

Figure 1: Correlogram of residuals for ARIMA $(1,1,0)$ model 
To increase the accuracy of the results, LjungBox test was applied on the model residuals as shown in table (7) below.

Table 7: Ljung-Box test results

\begin{tabular}{|c|c|c|c|c|}
\hline النموذج & df & $\boldsymbol{Q}_{\boldsymbol{L} \boldsymbol{B}}$ & $\chi^{\mathbf{2}}(\boldsymbol{d} \boldsymbol{f}, \boldsymbol{a l p h a}=\mathbf{0 . 0 5})$ & p-value \\
\hline $\operatorname{ARIMA}(1,1,0)$ & 23 & 15.4305 & 35.172 & 15.4305 \\
\hline
\end{tabular}

By testing the P-value, we accept the null hypothesis and conclude that the residuals of ARIMA $(1,1,0)$ model are completely random and represent the white noise. Therefore, ARIMA $(1,1,0)$ model represent the best model to estimate the exchange rate

\section{6- Artificial neural network methodology application}

The main step in designing the neural network model of a specific time series is determining the number of input variables. Based on the results of Box-Jenkins methodology that showed ARIMA $(1,1,0)$ model as the best model to represent the data, we conclude that the input variables include the $\mathrm{Y}_{\mathrm{t}-1}$ only. Therefore, the number of input nodes equal to one. Because the goal here is to predict one-step-a head, one.

output node was set in the output layer, which include one variable $\mathrm{Y}_{\mathrm{t}}$. In addition, one hidden layer was determined for the hidden level. By choosing backpropagation algorithm to train the network, a 0.5 learning speed and 0.9 momentum were selected, and we include $100 \%$ of the data for the training due to the small sample size.

Because there is no constant rule to select the activation functions in both the hidden and output layers, 5 models including $\mathrm{ANN}(1), \mathrm{ANN}(2), \mathrm{ANN}(3), \mathrm{ANN}(4)$, and ANN(5) were built with different activation functions as shown in table (8). Based on the activation function in the output layer of each model, the processing formula was determined. The number of hidden nodes in each models were also determined based on the try and error approach and the following formulas:

Number of hidden nodes $=\mathrm{R}$

Number of hidden nodes $=2 \mathrm{R}$

Number of hidden nodes $=2 \mathrm{R}+1$

Where $\mathrm{R}$ represents the number of the input nodes. 
Table 8: Artificial neural networks models

\begin{tabular}{|c|c|c|c|c|c|c|c|c|}
\hline \multirow{9}{*}{ 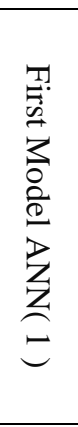 } & \multicolumn{3}{|c|}{ Activation function for hidden layer } & \multicolumn{5}{|c|}{ Hyperbolic tangent } \\
\hline & \multicolumn{3}{|c|}{ Activation function for output layer } & \multicolumn{5}{|c|}{ sigmoid } \\
\hline & \multicolumn{3}{|c|}{ Data preprocessing formula } & \multicolumn{5}{|c|}{ normalized } \\
\hline & $\begin{array}{c}\text { Number of Hidden } \\
\text { Nodes }\end{array}$ & MSE & MAE & MAPE & $\begin{array}{c}\text { Number of Hidden } \\
\text { Nodes }\end{array}$ & MSE & MAE & MAPE \\
\hline & 1 & 355.3003 & 13.8103 & 1.0669 & 6 & 244.4384 & 10.8591 & 0.8442 \\
\hline & 2 & 239.2133 & 10.7915 & 0.8421 & 7 & 240.6842 & 10.4926 & 0.8174 \\
\hline & 3 & 314.3509 & 12.3766 & 0.96 & 8 & 320.4959 & 12.2783 & 0.9625 \\
\hline & 4 & 363.1231 & 14.0481 & 1.0874 & 9 & 268.5468 & 11.936 & 0.9279 \\
\hline & 5 & 299.6979 & 12.6116 & 0.9751 & 10 & 276.1918 & 11.8453 & 0.9259 \\
\hline \multirow{9}{*}{ 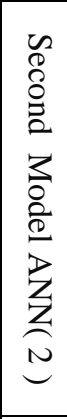 } & \multicolumn{3}{|c|}{ Activation function for hidden layer } & \multicolumn{5}{|c|}{ sigmoid } \\
\hline & \multicolumn{3}{|c|}{ Activation function for output layer } & \multirow{2}{*}{\multicolumn{5}{|c|}{$\begin{array}{c}\text { sigmoid } \\
\text { normalized }\end{array}$}} \\
\hline & \multicolumn{3}{|c|}{ Data preprocessing formula } & & & & & \\
\hline & $\begin{array}{c}\text { Number of Hidden } \\
\text { Nodes } \\
\end{array}$ & MSE & MAE & MAPE & $\begin{array}{c}\text { Number of Hidden } \\
\text { Nodes } \\
\end{array}$ & MSE & MAE & MAPE \\
\hline & 1 & 308.7995 & 12.6732 & 0.98 & 6 & 400.6688 & 13.8814 & 1.0779 \\
\hline & 2 & 399.0621 & 14.5312 & 1.0978 & 7 & 366.3151 & 14.5746 & 1.1027 \\
\hline & 3 & 337.6484 & 12.7363 & 1.0029 & 8 & 272.8888 & 9.5703 & 0.7261 \\
\hline & 4 & 246.7104 & 10.5956 & 0.8088 & 9 & 297.0384 & 12.5679 & 0.9652 \\
\hline & 5 & 256.438 & 11.5061 & 0.8838 & 10 & 272.4871 & 11.658 & 0.9101 \\
\hline \multirow{9}{*}{ 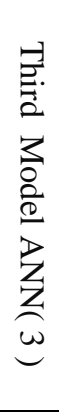 } & \multicolumn{3}{|c|}{ Activation function for hidden layer } & \multicolumn{5}{|c|}{ Hyperbolic tangent } \\
\hline & \multirow{2}{*}{\multicolumn{3}{|c|}{$\begin{array}{l}\text { Activation function for output layer } \\
\text { Data preprocessing formula }\end{array}$}} & \multirow{2}{*}{\multicolumn{5}{|c|}{$\begin{array}{c}\text { Identity } \\
\text { normalized }\end{array}$}} \\
\hline & & & & & & & \multicolumn{2}{|c|}{ normalized } \\
\hline & $\begin{array}{l}\text { Number of Hidden } \\
\text { Nodes }\end{array}$ & MSE & MAE & MAPE & $\begin{array}{l}\text { Number of Hidden } \\
\text { Nodes }\end{array}$ & MSE & MAE & MAPE \\
\hline & 1 & 177.339 & 7.6599 & 0.5865 & 6 & 184.5194 & 8.0842 & 0.6196 \\
\hline & 2 & 173.3501 & 7.6115 & 0.5843 & 7 & 196.4128 & 8.754 & 0.6751 \\
\hline & 3 & 198.175 & 8.6334 & 0.6629 & 8 & 179.8835 & 7.9118 & 0.6056 \\
\hline & 4 & 183.9683 & 8.0917 & 0.6195 & 9 & 182.1894 & 7.9497 & 0.6101 \\
\hline & 5 & 183.2493 & 7.9365 & 0.6103 & 10 & 184.5148 & 8.1362 & 0.6227 \\
\hline \multirow{9}{*}{ 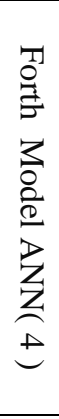 } & Activation $\mathrm{ft}$ & tion for hic & den layer & & & gmoid & & \\
\hline & Activation $\mathrm{fu}$ & tion for out & but layer & & & dentity & & \\
\hline & Data pre & cessing for & mula & & & malized & & \\
\hline & $\begin{array}{c}\text { Number of Hidden } \\
\text { Nodes }\end{array}$ & MSE & MAE & MAPE & $\begin{array}{c}\text { Number of Hidden } \\
\text { Nodes } \\
\end{array}$ & MSE & MAE & MAPE \\
\hline & 1 & 211.7407 & 9.3136 & 0.7118 & 6 & 182.8886 & 8.0308 & 0.6238 \\
\hline & 2 & 222.3407 & 9.6718 & 0.7421 & 7 & 198.721 & 8.6888 & 0.6715 \\
\hline & 3 & 185.2495 & 8.2581 & 0.6293 & 8 & 181.8466 & 7.9717 & 0.6123 \\
\hline & 4 & 195.651 & 8.7934 & 0.6728 & 9 & 220.4262 & 9.1451 & 0.7009 \\
\hline & 5 & 191.5193 & 8.686 & 0.6657 & 10 & 185.0319 & 8.1435 & 0.6259 \\
\hline & Activation $\mathrm{ft}$ & tion for hic & den layer & & Нур & olic tangen & & \\
\hline 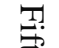 & Activation $\mathrm{ft}$ & tion for out & but layer & & Нyp & olic tangen & & \\
\hline 自 & Data pre & cessing for & mula & & Adju & d normalize & & \\
\hline 3 & $\begin{array}{c}\text { Number of Hidden } \\
\text { Nodes }\end{array}$ & MSE & MAE & MAPE & $\begin{array}{c}\text { Number of Hidden } \\
\text { Nodes }\end{array}$ & MSE & MAE & MAPE \\
\hline 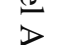 & 1 & 298.7304 & 12.7281 & 0.9971 & 6 & 307.0816 & 12.5883 & 0.992 \\
\hline 2 & 2 & 183.2822 & 8.6717 & 0.6709 & 7 & 284.4868 & 11.752 & 0.9224 \\
\hline & 3 & 175.6466 & 8.3228 & 0.6452 & 8 & 267.8135 & 11.5292 & 0.899 \\
\hline & 4 & 274.034 & 11.7873 & 0.9162 & 9 & 281.4044 & 11.748 & 0.923 \\
\hline & 5 & 283.5786 & 11.9748 & 0.9335 & 10 & 304.3154 & 12.8228 & 1.0107 \\
\hline
\end{tabular}


Regardless the number of the hidden nodes, by examining table (8) and based on MSE, MAE, and MAPE criteria, the best model among the designed models is ANN (3). Therefore, we conclude that the best activation function for the hidden layer is the bipolar function and the linear function for the output layer. In addition, by testing the third model, it is apparent that the best number of nodes for the hidden layer is 2 .
Therefore, we conclude that the best formula to determine the number of hidden nodes is $2 \mathrm{R}$.

Based on the third model ANN (3) with 2 nodes and constant requirements of the other network except the sample size, data was divided to two sets including the training and the testing with specific portions as shown in table (9). The network was retrained again and the results are shown in table (9).

Table 9: Values of the criteria when data partitioning

\begin{tabular}{|c|c|c|c|c|}
\hline Training Data & Testing Data & MSE & MAE & MAPE \\
\hline 100 & 0 & 173.3501 & 7.6115 & 0.5843 \\
\hline 90 & 10 & 184.357 & 8.2431 & 0.6318 \\
\hline 80 & 20 & 183.1978 & 7.2871 & 0.5619 \\
\hline 70 & 30 & 180.9971 & 7.763 & 0.5966 \\
\hline 60 & 40 & 188.8886 & 7.575 & 0.5855 \\
\hline 50 & 50 & 179.1047 & 7.9445 & 0.6062 \\
\hline 40 & 60 & 198.5476 & 9.2811 & 0.7166 \\
\hline 30 & 70 & 189.0676 & 8.8814 & 0.674 \\
\hline 20 & 80 & 204.1265 & 8.046 & 0.6266 \\
\hline 10 & 90 & 185.3909 & 7.3814 & 0.573 \\
\hline
\end{tabular}

By examining table (9), we conclude that the inclusion of all the data in the training leads to the lowest potential error. This is clear through the MSE criterion that reach its lowest value when $100 \%$ of the data is included in the training, which indicates a safe primary selection of the data size.
Based on the third model with 2 hidden nodes and constant network requirements except the momentum value, different models were designed with different momentum values as shown in table (10) below.

Table 10: Values of the criteria during momentum change and fixed learning rate

\begin{tabular}{|c|c|c|c|c|c|}
\hline Learning Rate & Momentum & Time & MSE & MAE & MAPE \\
\hline 0.5 & 0.9 & $0: 00: 00.09$ & 173.3501 & 7.6115 & 0.5843 \\
\hline 0.5 & 0.8 & $0: 00: 00.08$ & 184.3754 & 8.1804 & .6289 \\
\hline 0.5 & 0.7 & $0: 00: 00.05$ & 171.2072 & 7.4626 & .5748 \\
\hline 0.5 & 0.6 & $0: 00: 00.05$ & 170.5924 & 7.5583 & .5800 \\
\hline 0.5 & 0.5 & $0: 00: 00.17$ & 188.2508 & 8.3374 & .6406 \\
\hline 0.5 & 0.4 & $0: 00: 00.37$ & 180.5767 & 7.9174 & .6067 \\
\hline 0.5 & 0.3 & $0: 00: 00.08$ & 173.5609 & 7.5861 & .5816 \\
\hline 0.5 & 0.2 & $0: 00: 00.03$ & 171.6374 & 7.3010 & .5630 \\
\hline 0.5 & 0.1 & $0: 00: 00.09$ & 197.1893 & 8.9972 & .6925 \\
\hline
\end{tabular}


By examining table (10), we conclude that the momentum value affects the training time and the error calculated by the network. We also conclude that the best value of momentum that gives the lowest possible error at appropriate time with 0.5 learning rate is 0.6 .
Based on the last modifications of the third model of the network, a comparison was conducted between the network training without data processing and the network training with data processing by using normalized formula. The results are shown in table(11).

Table 11: Values of criteria for final model without processing

\begin{tabular}{|c|c|c|c|}
\hline Final Model & MSE & MAE & MAPE \\
\hline Without Processing & 13345.0652 & 99.8602 & 7.5583 \\
\hline With Processing & 170.5924 & 7.5583 & .5800 \\
\hline
\end{tabular}

By examining table (11), we conclude that data processing is a crucial step before providing the network with data. This is apparent through the values of MSE, MAE, and MAPE criteria as shown in table (11).

Therefore, the best model of the neural network that can be used in the estimation is the third model with 2 hidden nodes and 0.6 momentum at 0.5 learning rate.

By comparing the calculated values of MSE, MAE, and MAPE for both models ARIMA $(1,1,0)$ and AAN (3) using Box-Jenkins and the neural network respectively, we conclude that the best methodology in forecasting the exchange rate is Box-Jenkin methodology as shown

below.

\begin{tabular}{|c|c|c|c|}
\hline methodology & MSE & MAE & MAPE \\
\hline Box-Jenkins & 156.0669 & 6.867803 & 0.005323 \\
\hline artificial neural networks & 170.5924 & 7.5583 & .5800 \\
\hline
\end{tabular}

\section{7- Conclusions:}

1- The series of exchange rate of Iraqi dinar to the US dollar is non-stationary in the mean and the variance.

2- The best model in forecasting the exchange rate using Box-Jenkins methodology is ARIMA $(1,1,0)$.

3- The best model of the artificial neural network to forecast the exchange rate using backpropagation algorithm is the network designed with one variable $\left(\mathrm{Y}_{\mathrm{t}}\right)$, hyperbolic activation function in the hidden layer and linear activation function in the output layer, learning rate of (0.5), (0.6 ) momentum, and two hidden nodes in one hidden level.

4- Based on the MSE, MAE and MAPE criterion, it is apparent that Box-Jenkins methodology is better than the neural network in forecasting the exchange rate of Iraqi dinar to the US dollar.

\section{8- Recommendations:}

1- Compare the backpropagation network and the Jordan or Elman network in predicting the exchange rate.

2- Apply the hybrid methodology to predict the exchange rate. Then compare the hybrid model and the pure neural network model to choose the best. 


\section{References}

1. Box,G.B.;Jenkins,G.M.\&Reinsel,G.C. ;(2008); "Time Series Analysis: Forecasting and Control" John Wiely \& Sons, New Jersey.

2. Hanke, J.E. \& Wichern,D.W.;(2009); "Business Forecasting" PHI Learning; U.S.A.

3. Wei,W.W.;(2006);"Timè Series Analysis :Univariate and Multivariate Methods" ;United states of America; Pearson Addison Wesley.

4. Montgomery,D.C.; Jennings,C.L. \& Kulahci,M.;(2015); "Introduction to time series analysis and forcasting" ;John Wiley \& Sons; New Jersey.

5. Shumway, R.H. \& Stoffer, D.S. ;(2011); "Time Series Analysis and Its Applications With R Examples" ;Springer; New York.

6. Wolters, J Kirchgassner,G.;(2007(; "Introduction to modern time series analysis" ;Springer; New York.

7. Chatfield, C.;(2004); "The analysis of time series: An introduction" ;NewYork; Chapman \& Hall/CRC.

8. Garrett,L.C. \& Fogarty,K.;(2012); "Using Box-Jenkins Modeling Techniques to Forecast Future Disease Burden and Identify Disease Aberrations in Public Health Surveillance Report" ; P.HD Dissertation, Western Michigan University.

9. Agami,N.;Atiya,A.;Saleh,M.\&El Shishiny, H.;(2009); Aneural network based dynamic forecasting model for Trend Impact Analysis" ;Elsevier; Vol.76; No.7; P.P: 952-962.
10. Hagan, M.T. \& Demuth, H.B.;(2008); "Neural Network Design" ;Amazon; 2nd Edtion .

11. Khashei,M. \& Bijari,M.;(2010); "An artificial neural network (p,d,q) model for time series forecasting" ;Elsevier; Vol. 37; No.1; P.P: 479 - 489.

12. Kulkarni, M.A.; Patil, S.; Rama, G.V. \& Sen, P.N.;(2008); "Wind speed prediction using statistical regression and neural network" ;Journal of Earth System Science; Vol. 117; No.4; P.P: 457-463.

13. Meng, X.; Jia,M. \& Wang,T.;(2014); "Neural network prediction of biodiesel kinematic viscosity at 313 K" ;Elsevier; Vol. 121; P.P: 133-140.

14. Oancea, B. \&Ciucu, S.C.;(2014);"Time series forcasting using neural networks" ;Cornell university library; P.P:1403-1408.

15. Yixin,Z. \& Zhang,J. ;(2010);"Stock Data Analysis Based on BP Neural Network" ;IEEE.

16. Zhang,G.P. \& Qi,M. ;(2005); "Neural network forecasting for seasonal and trend time series" ;Elsevier; Vol. 160; No. 2; P.P: 501 - 514.

17. Zurada, J.M.;(1992); "Introduction to Artificial Neural Systems" ;west ppublishing company; United States of America.

18. Tarsauliya, A.; Kant, S. \& Kala,R.;(2010); "Analysis of Artificial Neural Network for Financial Time Series Forecasting" ; International Journal of Computer Applications; Vol. 9; No.5

19. Suzuki,K. ;(2011).; "Artificial Neural Networks- Methodological Advances and Biomedical Applications" ; InTech; India. 
التنبؤ باستخدام اساليب الثبكات العصبية الاصطناعية وبوكس جينكنز: دراسة مقارنة

$$
\begin{aligned}
& \text { محمد حبيب الثاروط } \\
& \text { جامعة القادسية } \\
& \text { كلية الادارة واقتصاد } \\
& \text { قسم الاحصاء }
\end{aligned}
$$

m.alsharood@gmail.com

\author{
ايمان يوسف عبد عون \\ جامعة القادسية \\ كلية علوم الحاسوب وتكنولوجيا المعلومات \\ قسم الرياضيات
}

emaan.yousif1991@gmail.com

المستخلص :

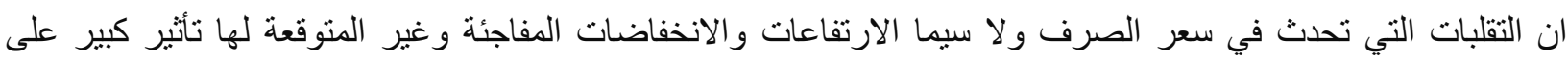

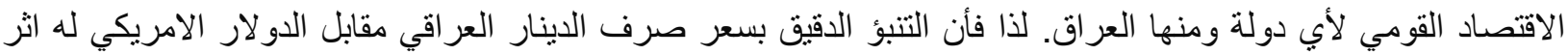

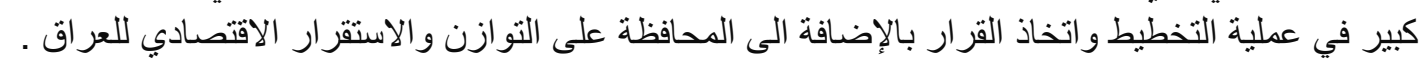

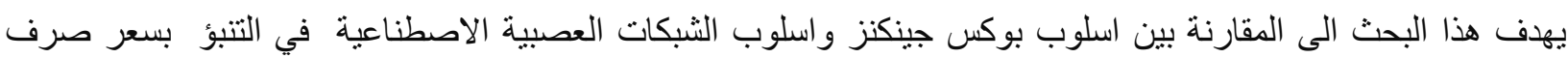

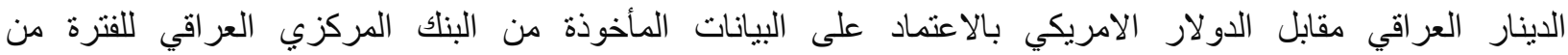
30/12/2014 30/01/2004 الى الى

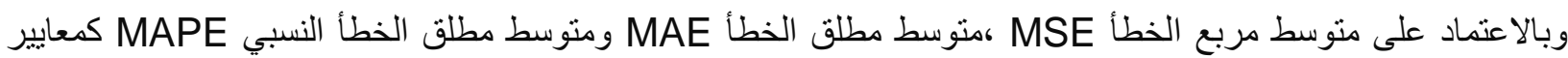
احصائية للمفاضلة بين الاسلوبين نم التوصل الى ان اسلوب النوب بوكس جينكنز أفضل من اسلوب الثبكة العصبية الاصطناعية في 